\title{
EVALUASI PRODUK DAN PELAYANAN DI PAYLESS BINTARO XCHANGE MENGGUNAKAN SERVICE QUALITY
}

\author{
Elvany Febiant, Sara Triana, Chairul Ardiansyah \\ Program Studi Manajemen, Universitas Pembangunan Jaya, Tangerang Selatan
}

\begin{abstract}
Abstrak
Jasa merupakan suatu bentuk kegiatan yang dilakukan oleh satu orang atau lebih, umumnya sifat jasa adalah tidak berbentuk dan tidak menghasilkan kepemilikan. Jasa adalah iniangibility (tidak berwujud dan terpengaruh dengan penjualan sebelumnya) karena jasa yang dibeli pelanggan tidak dapat dihitung, diukur maupun disimpan untuk ditentukan kualitas jasanya. Toko Payless merupakan suatu toko yang bergerak di bidang industri sepatu, payless merupakan salah satu brand yang tersebar di berbagai Negara termasuk di Indonesia, harga yang di tawarkan brand ini terbilang murah. Dalam upaya meningkatkan kunjungan konsumen, sebanyak mungkin Payless dapat mencapai target pemasaran yang terpadu. Pengumpulan data dalam penelitian terdiri dari 2 langkah yaitu Persiapan, tahap ini dilakukan sebelum melakukan penelitian seperti mencari buku, jurnal dan landasan teori yang mendukung penelitian seperti teori kualitas jasa dan servqual. Isi kuisioner yang disusun mewakili 5 dimensi dalam kualitas jasa. Kesimpulan penelitian adalah Atribut pernyataan yang sudah memenuhi harapan pelanggan tidak ada yang bernilai positif.
\end{abstract}

Kata Kunci: jasa, Payless, servqual, kualitas jasa

\section{PENDAHULUAN}

Toko Payless merupakan suatu toko yang bergerak di bidang industri sepatu, payless merupakan salah satu brand yang tersebar di berbagai Negara termasuk di Indonesia, harga yang di tawarkan brand ini terbilang murah. Namun, kualitas tak berbanding dengan harga. Payless menjamin kualitas yang sangat kuat. Pada tahun 2010, perusahaan ini mengoperasikan hampir 4.500 toko. Selama lebih dari 50 tahun, payless telah melayani jutaan konsumen di tokonya yang terletak di berbagai lokasi seperti di Amerika Serikat. Strategi Payless adalah berfokus pada kebutuhan konsumen dalam hal ini produk uptodate dengan alas kaki yang nyaman. Dilihat dari pencapaian yang dimiliki oleh Payless dengan jumlah penjualan per tiga bulan dan mampu masuk dalam persaingan dengan perusahaan bisnis lain. Payless berdiri dengan store layout, promosi, harga, serta merek dengan penerapan strategi pemasarannya dengan faktor internal pada toko yaitu: produk dan kualitas pelayanan. Pada penerapan strategi pemasaran Payless dengan toko retail sepatu impor pada umumnya memberikan kemudahan dalam mencari sepatu dan ukuran sepatu yang diinginkan. Penempatan produk di Payless berupa loronglorong dan ukuran sepatu serta dibedakan penempatan berdasarkan gender. Adapun cara kerja Payless, dalam melakukan promosi pelayanan melalui media yaitu papan iklan serta media sosial. Dalam upaya meningkatkan kunjungan konsumen, sebanyak mungkin Payless dapat mencapai target pemasaran yang terpadu.

Oleh karena itu, peneliti melakukan studi tentang "Evaluasi Produk dan Pelayanan di Payless Bintaro XChange Menggunakan Service Quality" berdasarkan lima dimensi jasa Servqual. Diharapkan dengan hasil penelitian nantinya dapat membuat Payless memaksimalkan kualitas pelayanannya. Berdasarkan latar belakang yang telah dikemukakan, maka rumusan masalah pada penelitian ini adalah mengidentifikasi atribut yang harus di evaluasi dan diperbaiki (tidak memenuhi harapan pelanggan), 
atribut yang perlu dipertahankan (berhasil memenuhi harapan pelanggan), atribut yang sudah memenuhi harapan pelanggan dan atribut yang perlu di evaluasi dan diperbaiki oleh Payless.

\section{Kualitas Jasa}

\section{LANDASAN TEORI}

"Jasa merupakan suatu bentuk kegiatan yang dilakukan oleh satu orang atau lebih, umumnya sifat jasa adalah tidak berbentuk dan tidak menghasilkan kepemilikan. Jasa adalah iniangibility (tidak berwujud dan terpengaruh dengan penjualan sebelumnya) karena jasa yang dibeli pelanggan tidak dapat dihitung, diukur maupun disimpan untuk ditentukan kualitas jasanya. Selain itu jasa juga bersifat heterogentty karena kinerja sangat bervariasi untuk setiap produsen maupun konsumen sehingga sulit untuk menjamin konsistensi perilaku pemberi jasa supaya seragam. Kualitas jasa adalah jasa yang diharapkan pelanggan (expected service) dan jasa yang dipersepsikan pelanggan (perceived service) atau P-E yaitu perception-minus-expectations. Kualitas jasa sebagai tingkat kesempurnaan yang diharapkan dan pengendalian atas kesempuraan tersebut untuk memenuni keinginan pelanggan. Kualitas jasa meliputi kualitas fungsi (functional quality), kualitas teknis (technical quality), dan citra pelanggan (corporate image).

\section{Metode Service Quality (Servqual)}

Kualitas pelayanan jasa adalah kesenjangan atau gap dalam suatu pelayanan dapat terjadi pada bagian pelanggan (yaitu antara pelayanan yang diharapkan pelanggan dengan pelayanan yang diterimanya) dan pada bagian penyedia jasa. Kualitas pelayanan menjadi suatu keharusan yang harus dilakukan perusahaan supaya mampu bertahan dan tetap mendapat kepercayaan pelanggan. Keberhasilan perusahaan dalam memberikan pelayanan yang berkualitas dapat ditentukan dengan pendekatan kualitas pelayanan yang telah dikembangkan. Kualitas adalah sesuatu yang diputuskan oleh pelanggan. Artinya, kualitas didasarkan pada pengalaman aktual pelanggan atau konsumen terhadap produk atau jasa yang diukur berdasarkan persyaratan-persyaratan tersebut. Konsep kualitas layanan yang diharapkan dan dirasakan ditentukan oleh kualitas layanan. Definisi kualitas jasa adalah ukuran sejauh mana suatu pelayanan yang diberikan dapat memenuhi harapan pelanggan.

\section{METODOLOGI PENELITIAN}

Jenis penelitian yang digunakan dalam penelitian ini adalah penelitian kuantitatif. Menurut Sugiyono (2012), metode penelitian kuantitatif dapat diartikan sebagai metode penelitian yang berlandaskan pada filsafat positivisme, digunakan untuk meneliti pada populasi atau sampel tertentu. Pengumpulan data dalam penelitian terdiri dari 2 langkah yaitu Persiapan, tahap ini dilakukan sebelum melakukan penelitian seperti mencari buku, jurnal dan landasan teori yang mendukung penelitian seperti teori kualitas jasa dan servqual. Melakukan studi pendahuluan dan studi literatur untuk lebih memahami topik yang diteliti dan merancang kuesioner. Isi kuisioner yang disusun mewakili 5 dimensi dalam kualitas jasa. Tahap kedua adalah Pengamatan, tahap ini memberikan kuesioner kepada responden, menggunakan metode simple random sampling. Jumlah responden dalam penelitian ini adalah 40 responden. Setelah melakukan penyebaran kuisoner dan mendapatkan data 40 responden, maka langkah selanjutnya adalah melakukan pengolahan data dengan metode Servqual. Metode ini dimulai dengan menghitung gap/selisih antara harapan pelanggan mengenai layanan jasa dengan kenyataan pelayanan yang dirasakan pelanggan.

\section{ANALISIS DAN PEMBAHASAN}

\section{Hasil Perhitungan Gap}

Tabel 1 menunjukkan hasil perhitungan gap/selisih antara harapan dan persepsi pelanggan terhadap pelayanan jasa berdasarkan 12 atribut pernyataan kuisioner. 
Tabel 1 Nilai Rata-Rata Gap 5 Terhadap Pernyataan Kualitas Layanan Jasa

\begin{tabular}{cccccc}
\hline Atribut & \multicolumn{2}{c}{ Harapan Pelayanan } & \multicolumn{2}{c}{ Kenyataan Pelayanan } & \\
\cline { 2 - 5 } & Bobot Nilai & $\begin{array}{c}\text { Rata-Rata Nilai } \\
\text { Harapan }\end{array}$ & Bobot Nilai & $\begin{array}{c}\text { Rata-Rata Nilai } \\
\text { Kenyataan }\end{array}$ & Nilai Gap 5 \\
\hline 1 & 165 & 4.125 & 158 & 3.95 & -0.175 \\
\hline 2 & 172 & 4.3 & 162 & 4.05 & -0.25 \\
\hline 3 & 173 & 4.325 & 137 & 3.425 & -0.9 \\
\hline 4 & 168 & 4.2 & 158 & 3.95 & -0.25 \\
\hline 5 & 166 & 4.15 & 155 & 3.875 & -0.275 \\
\hline 6 & 172 & 4.3 & 156 & 3.9 & -0.4 \\
\hline 7 & 167 & 4.175 & 148 & 3.7 & -0.475 \\
\hline 8 & 169 & 4.225 & 153 & 3.825 & -0.4 \\
\hline 9 & 174 & 4.35 & 153 & 3.825 & -0.525 \\
\hline 10 & 161 & 4.025 & 147 & 3.675 & -0.35 \\
\hline 11 & 163 & 4.075 & 147 & 3.675 & -0.4 \\
\hline 12 & 175 & 4.375 & 171 & 4.275 & -0.1 \\
\hline
\end{tabular}

\section{Perhitungan Dimensi Kualitas Jasa Berdasarkan Servqual Gap 5}

Lima dimensi dalam kualitas jasa terdiri dari reliability (keandalan), responsiveness (daya tanggap), assurance (jaminan), empathy (empati), dan tangibles (bukti fisik). Tabel 2 menunjukkan hasil perhitungan nilai rata-rata gap 5 berdasarkan lima dimensi servqual.

Tabel 2 Nilai rata-rata Gap 5 berdasarkan dimensi servqual

\begin{tabular}{ccccccc}
\hline Dimensi & Atribut & $\begin{array}{c}\text { Jumlah } \\
\text { Rata-Rata } \\
\text { Harapan }\end{array}$ & $\begin{array}{c}\text { Rata-Rata } \\
\text { Kenyataan }\end{array}$ & $\begin{array}{c}\text { Nilai } \\
\text { Harapan } \\
\text { Pelayanan }\end{array}$ & $\begin{array}{c}\text { Nilai } \\
\text { Kenyataan } \\
\text { Pelayanan }\end{array}$ & $\begin{array}{c}\text { Nilai Gap } \\
5\end{array}$ \\
\hline Reliability & 11,12 & 8.45 & 7.95 & 4.225 & 3.975 & -0.25 \\
\hline Responsiveness & 9,10 & 8.375 & 7.5 & 4.18 & 3.75 & -0.43 \\
\hline Assurance & $3,4,5$ & 12.67 & 11.25 & 4.22 & 3.75 & -0.47 \\
\hline Empathy & $6,7,8$ & 12.7 & 11.42 & 4.23 & 3.80 & -0.43 \\
\hline Tangibles & 1,2 & 8.425 & 8 & 4.21 & 4 & -0.21 \\
\hline
\end{tabular}

Dari tabel 2 dapat diketahui dimensi yang memiliki gap terbesar sampai dengan yang terkecil. Semakin besar gap yang didapat dari perhitungan gap 5 maka semakin kurang baiknya kualitas pelayanan jasa tersebut. Dan sebaliknya, semakin kecil gap yang didapat dari perhitungan gap 5 (gap tersebut nol dan positif) maka semakin baik kualitas pelayanan jasanya. Oleh karena itu, prioritas perbaikan pelayanan jasa dilakukan dari gap atau kesenjangan terbesar. Berdasarkan tabel 2 dapat dilihat bahwa dimensi kualitas jasa Responsiveness (daya tanggap) dan Tangibles (bukti fisik) Disesuaikan dengan hasil studi memiliki gap tidak ada yang bernilai positif. Dimensi kualitas jasa Responsiveness memiliki nilai gap 0.43 , dimensi kualitas jasa Tangibles memiliki nilai gap -0.21, Reability memiliki nilai gap -0.25 , Assurance memiliki nilai gap -0.47 dan Empathy memiliki nilai gap -0.4. Dari 5 dimensi kualitas jasa ini belum berhasil memenuhi kepuasan pelanggan dan perlu adanya perbaikan.

Tabel 3 Urutan nilai Gap 5 dari Gap Terkecil Sampai Gap Terbesar Isi Tabel disesuaikan dengan hasil studi, diurutkan dari yang terbesar hingga terkecil sesuai dengan Tabel 1

\begin{tabular}{ccc}
\hline Atribut & Pernyataan & Nilai Gap 5 \\
\hline 12 & Lokasi mudah dijangkau & -0.1 \\
\hline 11 & Produk mudah dicari & -0.4
\end{tabular}




\begin{tabular}{ccc}
8 & Karyawan menyambut kedatangan pelanggan & -0.4 \\
\hline 6 & Karyawan bersikap ramah & -0.4 \\
\hline 3 & Produk lengkap & -0.9 \\
\hline 2 & Produk tersusun rapih & -0.25 \\
\hline 4 & Produk yang ditawarkan berkualitas baik & -0.25 \\
\hline 10 & Saran dan keluhan ditanggapi dengan baik & -0.35 \\
\hline 1 & Tempat nyaman dan bersih & -0.175 \\
\hline 5 & Kualitas produk sesuai harga & -0.275 \\
\hline 7 & Karyawan murah senyum & -0.475 \\
\hline 9 & Karyawan melayani dengan baik & -0.525 \\
\hline
\end{tabular}

Berdasarkan tabel 3, tidak terdapat atribut pernyataan yang bernilai gap positif (Perlu adanya evaluasi perbaikan) dan 12 atribut pernyataan yang bernilai gap negatif (perlu adanya evaluasi dan perbaikan). Atribut pernyataan yang bernilai positif tidak ada. Sedangkan atribut pernyataan nomor $12,11,8,6,3,2,4,10,1,5,7,9$ bernilai negatif.

\section{Kesimpulan}

\section{KESIMPULAN DAN SARAN}

1. Atribut pernyataan yang sudah memenuhi harapan pelanggan tidak ada yang bernilai positif.

2. Atribut pernyataan yang bernilai negatif (perlu adanya evaluasi dan perbaikan) diantaranya adalah atribut nomor 12 yaitu "Lokasi mudah dijangkau" yang bernilai -0.1, atribut nomor 11 yaitu "Produk mudah dicari" yang bernilai -0.4, atribut nomor 8 yaitu "Karyawan menyambut kedatangan pelanggan" yang bernilai -0.4, atribut nomor 6 yaitu "Karyawan bersikap ramah" yang bernilai -0.4, atribut nomor 3 yaitu "Produk lengkap" yang bernilai -0.9, atribut nomor 2 yaitu "Produk tersusun rapih" yang bernilai -0.25, atribut nomor 4 yaitu "Produk yang ditawarkan berkualitas baik" yang bernilai -0.25 , atribut nomor 10 yaitu "Saran dan keluhan ditanggapi dengan baik" yang bernilai -0.35 , atribut nomor 1 yaitu "Tempat nyaman dan bersih" yang bernilai -0.175 , atribut nomor 5 yaitu "Kualitas produk sesuai harga" yang bernilai -0.275 , atribut nomor 7 yaitu "Karyawan murah senyum" yang bernilai -0.475 , atribut nomor 9 yaitu "Karyawan melayani dengan baik" yang bernilai -0.525 . 


\section{References}

[1] Kotler, P., \& Keller, K. L. (2016). Marketing Management. UK: Pearson Education Limited.

[2] Sugiyono. (2012). Metode Penelitian Kuantitatif Kualitatif dan R\&D. Bandung: Alfabeta.

[3] Tannady, H. (2018). Psikologi Industri dan Organisasi. Yogyakarta : Penerbit Expert.

[4] Zeithaml, V. A., Parasuraman, A., \& Berry, L. L. (1985). Problem and Strategis in Service Marketing. Journal of Marketing, 49(2), 33-46.

[5] Wilujeng, F. R., Rembulan, G. D., Andreas, D., \& Tannady, H. (2019). Meningkatkan Kepuasan Pelanggan Pada Dua Bisnis E-Commerce Terbesar di Indonesia Dengan Menggunakan Analisis Servqual dan IPA. SEMNASTEK-Seminar Nasional Sains dan Teknologi 2019, hal. 1-9.

[6] Gabriella, P., \& Tannady, H. (2019). Pengaruh Motivasi dan Disiplin Kerja Terhadap Kinerja Guru di SMAN 8 Bekasi. Seminar Nasional Sains \& Teknologi Informasi (SENSASI), hal. 121-124.

[7] Tannady, H., Luin, J. A., \& Widhianto, C. W. (2019). Faktor-Faktor Determinan Performa Kerja Karyawan Ground Handling Pada Industri Penerbangan di Indonesia. Seminar Nasional Riset dan Inovasi Teknologi (SEMNAS RISTEK), hal. 413-418.

[8] Imon Wanda, Tumbel Altje, Mandagie Yunita. (2018). Analisis Faktor yang Mempengaruhi Keberhasilan dan Kegagalan pada Strategi Pemasaran.

[9] Lusiani, M., Yuirafat, A., \& Tannady, H. (2017). ANALISIS KEPUASAN PENGGUNA BPJS DAN NON BPJS TERHADAP LAYANAN RUMAH SAKIT DENGAN MODEL QUALITY FUNCTION DEPLOYMENT. Seminar Nasional Akuntansi dan Bisnis (SNAB), Fakultas Ekonomi Universitas Widyatama.

[10] Putriandari Siwi Aulia. (2012). Analisis Pengaruh Kualitas Jasa dan Kepuasan.

[11] Rahayu, M., Rasid, F., \& Tannady, H. (2018). Effects of Self Efficacy, Job Satisfaction, and Work Culture Toward Performance of Telemarketing Staff in Banking Sector. South East Asia Journal of Contemporary Business, Economics and Law, 16(5), 47-52.

[12] Rahayu, M., Rasid, F., \& Tannady, H. (2019). The Effect of Career Training and Development on Job Satisfaction and its Implications for the Organizational Commitment of Regional Secretariat (SETDA) Employees of Jambi Provincial Government. International Review of Management and Marketing, 9(1), 79-89.

[13] Reynaldo Yovan,Santoso Ricky Oey. (2013). Analisi Pengaruh Kualitas Layanan dan Kualitas Produk Terhadap Loyalitas Pelanggan de' EXCELSO Surabaya Town Square.

[14] Tannady, H., \& Sitorus, T. (2017). Role Of Compensation, Organization Culture, And Leadership On Working Motivation Of Faculty Member (Study Case : Universities In North Jakarta). IOSR-Journal of Business \& Management, 19(10), 41-47.

[15] Wiryono Kaderi Sudarso, Diahmarisa Trisatiani. (2016). Analisis Kualitas Pelayanan Jasa Penerbangan Studi Kasus: Garuda Indonesia Kelas Ekonomi.

[16] Tannady, H. (2017). Manajemen Sumber Daya Manusia. Yogyakarta : Penerbit Expert.

[17] Junaedi Shellyana, Junaedi C.Marliana. (2001). Mengukur Persepsi Harapan dan Kualitas Jasa Konsumen dengan Model Service Quality.

[18] Yuliana \& Tannady, H. (2019). FAKTOR DETERMINAN PERFORMA PEKERJA KONSTRUKSI MELALUI MEDIASI MOTIVASI. Journal of Business \& Applied Management, 12(2), 169-186.

[19] Adlan, R. S. (2017). Pengaruh Service Quality, Marketing Mix dan Kepuasaan Mahasiswa Terhadap Customer Loyalty.

[20] Ilham, M. (2019). Pengertian Jasa Menurut Para Ahli. Karakteristik, Klasifikasi\& Jenis Jasa. 